\title{
Inconsistency, Rationality and Relativism
}

\section{ROBERT C. PINTo University of Windsor}

Key words: deductive closure, doxastic commitment, epistemic appraisal, epistemic faults, epistemic relativism, inconsistency, maximizing truth and minimizing falsehood, rationality, relativism, self-contradiction.

Abstract: In section 1, I argue that the principal reason why inconsistency is a fault is that it involves having at least one false belief. In section 2 , I argue that inconsistency need not be a serious epistemic fault. The argument in section 2 is based on the notion that what matters epistemically is always in the final analysis an item's effect on attaining the goal of truth. In section 3 I describe two cases in which it is best from an epistemic point of view to knowingly retain inconsistent beliefs. In section $4 \mathrm{my}$ goal is to put into perspective the charge that relativism ought to be rejected because it involves one in inconsistency.

\section{Why is inconsistency a fault?}

Do I contradict myself?

Very well then I contradict myself, (I am large, I contain multitudes).

Wait Whitman, "Song of Myself," sct. 51 , in Leaves of Grass (1855).

Poets, apparently, are issued licenses to do things the rest of us are forbidden to do. Assume for the moment that as a poet Whitman is permitted to wallow in self-contradiction. What about the rest of us?

Since we are talking here about persons contradicting themselves or being inconsistent, I submit the following definition as useful for our purposes (' $A C$ ' stands for 'absence of consistency'):

AC $S$ is guilty of inconsistency if and only if there is a set $K$ of propositions such that (i) $S$ believes every member of $K$ and (ii) it is impossible that all the members of $K$ are true (i.e., necessarily at least one member of $K$ is false).

I can think of three reasons logicians might offer for saying that inconsistency so defined is a Bad Thing, i.e., is something to be avoided. Two of the three don't seem to me very good reasons; the third seems to me quite solid.

The first two reasons invoke the principle that a contradiction entails every proposition, that is to say ('EFQ' stands for ex falso quodlibit),

EFQ If $K$ is a set of propositions and if it is impossible that all the members of $K$ are true, then for any proposition $P, K$ entails $P$ (or again, the argument from $K$ to $P$ is deductively valid).

Though a few logicians would dispute the truth of EFQ, I have no desire to dispute it here.

Reason \#1. With EFQ in mind, someone might argue that if it is permissible to have inconsistent beliefs, then it is possible (or permissible) to prove anything. For persons with inconsistent beliefs can always form an argument whose premisses consist of some inconsistent subset of what they believe and whose conclusion is any arbitrarily chosen proposition. Given EFQ, such an argument would be deductively valid. And, as long as inconsistency is not a fault, its 
premisses would have to be judged acceptable, and so the argument would have to be judged a good one.

But the reasoning behind this objection is seriously flawed. For from the assumption that inconsistency as such is not a fault, it does not follow that we can't object to the use of inconsistent premisses in an argument. If a premiss set is demonstrably inconsistent, we can condemn any argument from that set as unsound, since it can be demonstrated that not all its premisses are true.

In other words, from the thesis that it isn't a fault for a person to be inconsistent it doesn't follow that arguments with demonstrably inconsistent premiss sets are OK.' And therefore it doesn't follow that anything and everything can be proved (where a proof is a deductively valid argument that does not beg the question and that has acceptable premisses).

Reason \#2. Consider the suggestion that if $\mathrm{P}$ entails $\mathrm{Q}$ then any person who believes $\mathrm{P}$ also believes $\mathrm{Q}$ - the suggestion, in other words, that a person's beliefs are closed under entailment. Virtually everybody concedes that application of deductive closure in such bald form is an implausible constraint on belief: people often don't see what the consequences of their current beliefs are and hence don't always embrace them. ${ }^{2}$ Nevertheless, there is a weaker version of the deductive closure principle that's not so obviously implausible:

\section{If (i) $K$ is a set of propositions and if (ii) $S$ believes every member of $K$ and if (iii) $K$ entails $Q$, then $S$ is committed to the truth of $Q$.}

In other words, even if I don't see (or even care) what the deductive consequences of my current beliefs are, I am "doxastically committed" to those consequences nonetheless.

Now it follows from our definition of inconsistency $(A C)$ and the principle DC, that people who are guilty of inconsistency are committed to the truth of every proposition-we might call this the AC/DC principle. And if we suppose that it's a mistake to balk at a proposition one is doxastically committed to, it will follow that people guilty of inconsistency are like the character in the musical Oklahoma who described herself as a "gal who can't say no." No matter what proposition they balk at, they are balking at a proposition they are doxastically committed to and which, therefore, they are not entitled to balk at.

I concede that there's something wrong with balking at a proposition that you are doxastically committed to. But that very concession leads me to question the acceptability of DC. Consider this. If a necessary proposition is entailed by every proposition (a counterpart if not a consequence of EFQ), then by DC every believer is committed to the truth of every necessary proposition. From this it follows that it's always a mistake to balk at a necessary proposition. But surely that can't be right. Reasonable mathematicians standardly refuse to accept mathematical truths until they can see that they are in fact mathematical truths.

Let me suggest an alternative way of formulating a principle for doxastic commitment: 


\section{$D^{*}$ If (i) $\mathrm{K}$ is a set of propositions and if (ii) $\mathrm{S}$ believes every member of $\mathrm{K}$ and if (iii) the inference from $K$ to $Q$ is one that $S$ ought to accept, then $\mathrm{S}$ is committed to the truth of $\mathrm{Q}$.}

$\mathrm{DC}^{*}$ is, in part, an attempt to capture the idea that we are committed to the more or less obvious consequences of what we already believe. This principle leaves mathematicians with the right to withhold assent from mathematical theorems whose truth hasn't been shown. But it also makes it easy for us to avoid the conclusion that a person guilty of inconsistency is committed to the truth of any and every proposition. To avoid that conclusion, we need only maintain that inferences with inconsistent premisses (or, perhaps, with demonstrably inconsistent premisses) are not inferences that ought to be

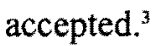

Reason \#3. There is, nevertheless, what I take to be a conclusive reason for saying that inconsistency is a Bad Thing. For it follows from AC, our definition of inconsistency, that necessarily anyone who is guilty of inconsistency believes at least one proposition which is not true. And if it is, as I believe, a Bad Thing to believe a proposition that is not true and if, moreover, whatever necessarily involves a Bad Thing is a Bad Thing, then inconsistency is a Bad Thing. Q.E.D.

The moral I want to draw from these considerations is a moral about why inconsistency is a fault. It is a fault because, and principally because, inconsistency requires having at least one belief that is false.

\section{How serious a fault is inconsistency?}

I want to maintain that inconsistency as such is not a serious epistemic fault. It does not follow from this that every case of inconsistency is relatively harmless, but only that a case of inconsistency need not be a serious epistemic flaw. My motive in making this claim is to pave the way for the idea that some epistemic faults are worse than inconsistency and that therefore in some cases the price of avoiding inconsistency will be too high. In such cases, it will be reasonable to rest, though perhaps not to wallow, in inconsistent beliefs; this will be the subject of section 3 below.

First, a word or two about epistemic "faults" and how we might judge their seriousness. I assume that in the epistemic as well as the ethical order, right and wrong (and virtue and vice) are to be assessed in the light of goals or aims. ${ }^{4}$ I also assume that in the epistemic order a prime goal is, to put it crudely, maximizing truth while minimizing falsehood. Other things being equal, from the epistemic point of view one should aim at increasing the "number" of one's true beliefs while decreasing the "number" of false ones. This is, at best, a very rough way of putting it, since (1) there's no unproblematic way of counting beliefs, ${ }^{5}(2)$ it leaves out of account the fact that some truths are a lot more important than others, ${ }^{6}$ and (3) it offers no guidance on how to balance the subgoal of acquiring truth against the subgoal of avoiding error.

Let us call this goal, however we ultimately refine our account of it, the "truth goal." We can suppose that epistemic appraisal of what a person does or 
thinks will be appraisal in light of the truth goal. There is a variety of ways this idea might be unpacked. Here's one way of doing it. Epistemic virtues and vices are those character traits that facilitate or inhibit attaining the truth goal.' Actions and omissions ${ }^{8}$ are epistemically right or wrong depending on how they affect the attainment of the truth goal-using a test that's likely to give an erroneous result is epistemically wrong in this regard; spending a lot of time on an inquiry that can only generate a lot of correct but insignificant detail will be epistemically wrong if the time could have been spent on an inquiry likely to unearth a few very important facts. A particular belief is epistemically OK (i.e., justified) if and only if acquiring and/or maintaining it is in accordance with sound epistemic strategies, and sound epistemic strategies are those which promote the attainment of the truth goal. (The latter would amount to something like rule utilitarianism with respect to the epistemic rightness of beliefs.) $)^{9}$

In the preceding paragraph I was trying only to make the idea of appraisal in light of the truth goal more concrete by illustrating one way in which that idea could be developed. The details of that development are not essential to my purposes here. What comes next is, however, essential to my purposes.

Epistemic faults will be more or less serious relative to each other, depending on the degree to which they inhibit the attainment of the truth goal. Other things being equal, a fault which deprives me of more truth, or involves me in more error, is worse than a fault which deprives me of less truth or involves me in fewer errors. In addition, a fault which deprives me of a more important truth will be worse than a fault that deprives me of a less important truth and also perhaps worse than a fault which involves me in a less significant error. An example or two might help. Suppose Uncle Harry constantly pronounces on matters he knows nothing about, usually getting them wrong, but despite this I'm a sucker for what he says. (This is a bit like the habit of believing what you read in the newspapers: we all know that a good chunk of what's printed there is false, but most of us are strongly inclined to believe whatever the papers say anyway). The inclination to believe Uncle Harry's uncorroborated testimony is an epistemic fault (more specifically, an epistemic vice). It is, moreover, a more serious fault than the inclination to believe Aunt Rachel's uncorroborated testimony if Rachel, who believes just about everything Harry says but otherwise has sound and carefully considered opinions, only infrequently repeats what Harry has told her. Or again, suppose I have a totally incompetent psychotherapist whose opinions I'm addicted to and I'm also a gullible reader of the National Enquirer. My addiction to the opinions of my psychotherapist is an epistemically more serious fault than is my addiction to the National Enquirer-at least if the erroneous beliefs I acquire from my therapist are more serious errors than are those which fill the pages of the Enquirer.

Now I maintain in light of this account of epistemic fault that inconsistency is not, as such, a serious fault. That I'm guilty of inconsistency means only that I have at least one false belief. It does not require that I have many false beliefs or that any of the false beliefs I have constitute serious errors. Moreover, it's pretty clear that even if none of us is guilty of inconsistency, all of us have some beliefs 
that are both false and unjustified. So a person who is guilty of inconsistency need not be any further from the truth goal than every one of us is already.

I believe that this argument is a very strong argument for the conclusion that inconsistency as such is not a serious epistemic fault. I concede that the argument is not conclusive, since it depends on the assumption (a) that what matters epistemically is always in the final analysis an item's effect on the attainment of the truth goal, and also on the assumption (b) that inconsistency need not deprive us of many or important truths and is not likely to lead us into more errors or more serious errors than plain falsehoods are. I maintain that these assumptions are plausible, but concede that they may both be challenged.

First, "epistemic deontologists" might challenge assumption (a) by claiming there are standards of epistemic appraisal which don't turn on the attainment of the truth goal, which are always violated by inconsistency, and whose violation is always serious.

Both deontologists and teleologists might challenge assumption (b) by claiming that inconsistency is in fact likely to lead us away from many or important truths or likely to lead us into more errors or more serious errors than plain falsehoods are.

Nevertheless, I submit that since the assumptions of my argument are plausible, anyone who would dissent from its conclusion must challenge assumption (a) or assumption (b) by mounting a case for one or both of the counterclaims l've sketched in the preceding two paragraphs.

\section{When is it reasonable to tolerate inconsistency?}

A foolish consistency is the hobgoblin of little minds, adored by little statesmen and philosophers and divines.

Ralph Waldo Emerson in Essays, "Self-Reliance" (First Series, 1841).

Some faults are reprehensible; some are not. A person who reasons from a false premiss is guilty of some sort of epistemic fault; but where the person had every reason to believe the premiss true, and where the premiss provides strong support for the conclusion, that person has done nothing epistemically reprehensible. Indeed, the argument corresponding to her inference is cogent and in drawing her conclusion she does something epistemically praiseworthy.

A person who reasons from inconsistent premisses certainly is guilty of some sort of epistemic fault. And where premisses are demonstrably inconsistent-where the person knows, or ought to know, that the premisses are inconsistent-that person's inference is epistemically reprehensible. ${ }^{10}$ (When people cannot be expected to realise that their premisses are inconsistent, their guilt is not so clear-see note 10 above.)

What concerns me here, however, is not the use of inconsistent premisses in arguments and inferences, but rather the mere fact of holding inconsistent views. Moreover, I want to zero in on what $I$ take to be the interesting cases, which are the cases where a person holds the views knowing them to be inconsistent. For I 
want to argue that it need not be reprehensible to hold views which one knows are inconsistent-that indeed it can be quite reasonable to do so.

Let me begin with a simple sort of case in which, if l'm right, it's reasonable to be knowingly guilty of inconsistency. Suppose Jones believes the following five propositions:

i) His friend Smith is a certified Professional Engineer (P. Eng.)

ii) One is a Professional Engineer only if duly certified by the Society of Professional Engineers (SPE)

iii) The bylaws of the SPE specify what the requirements for certification are

iv) The bylaws stipulate that no one can be certified who does not have a degree from an accredited school of engineering, and that there are no exceptions to this rule

v) Smith's only degree is from a school which is not an accredited school of engineering

It is easy to imagine Jones having strong reason to believe each of these propositions (he's seen Smith's certification papers and knows that Smith carries out the duties of a certified P.Eng. in a reputable firm; he's actually read the bylaws of the SPE and researched government regulations concerning the practice of engineering; he's known Smith since childhood and therefore knows which schools Smith has attended, and personally researched the accreditation of the school from which Smith has his degree). It's now pointed out to Jones that it's impossible that (i)-(v) are all true. Jones has made a mistake somewhere-but where? Suppose there is no ready way for Jones to determine which of the five propositions is false. What is it then reasonable for him to do? There seem to be only three choices. (a) Stop believing all five propositions until he finds out-if he ever does-which one is wrong? (b) Arbitrarily select some proper subset and stop believing the members of that subset? (c) Continue to believe all five propositions, even though he realises they can't all be true?"

Intuitions about what Jones should do may vary. To me, alternative (b) seems clearly unreasonable-it would make Jones' belief set depend on an arbitrary choice. And alternative (a) doesn't do much better-to me it seems unwise to turn agnostic on five matters over a problem like this. As a result, my intuitions lead me to suppose that (c) is the reasonable course for Jones to take.

Moreover, if we look at this situation in terms of the truth goal, that intuition is quite defensible. Assuming only one of the five propositions is false, dropping four truths in order to avoid one falsehood does not get you closer to the truth goal, and arbitrarily dropping, say, one of the five gives only a one in five chance of avoiding a falsehood and a four in five chance of losing a truth. If truth is our goal, retaining the inconsistency under these circumstances is the best thing to do.

I claim that this is a situation in which it is reasonable for someone to retain an inconsistent set of beliefs. Of course, if Jones has a quick easy and way to determine which of the five propositions is the culprit, then it's no longer reasonable for him to tolerate the inconsistency: the reasonable thing then is to find out which of the five is false and thereby remove the inconsistency. 
Let me move to a second sort of case, much discussed in the literature under the title of the Preface Paradox. ${ }^{12}$ Jones carefully researches and writes a book on the native cultures of the American Southwest, and in the preface writes:

Though I've done everything possible to assure that the information which follows is correct, undoubtedly it still contains a few errors, and for this I apologise.

If Jones believes the proposition affirmed in the middle clause of this sentence, and also believes every other proposition affirmed in the book, then she will be guilty of inconsistency, since it is impossible that the set of propositions which contains this proposition and all the other propositions affirmed in the book contains only true propositions. ${ }^{13}$ Yet surely adding the disclaimer that gives rise to the inconsistency makes Jones more reasonable, not less reasonable. And though Jones clearly will, if reasonable, stop believing any proposition affirmed in the book when she discovers it is false, there's no proposition which she epistemically ought to stop believing before she unearths its falsehood. Moreover, it would be utterly unreasonable to give up on the entire book on the grounds that it contains a few errors.

In cases like these, it seems to me, retaining an inconsistency is the most reasonable thing to do.

\section{What about relativism?}

What bearing, if any, do these considerations have on the charge that relativism is unacceptable because (1) relativism is an inconsistent philosophical view and (2) any inconsistent view is unacceptable. If the story I'm telling is right, then the second assumption behind this charge is false. That, however, doesn't get us terribly far, since in some cases retaining an inconsistency is indeed unreasonable. But my story does shift the nature and focus of the attack: it will now be necessary to show that relativism involves an unacceptable form of inconsistency. In the space of a short paper I can't do much to advance discussion of what is, I hope you now agree, a complicated issue. I want, however, to offer a few remarks about the bearing of my story on what I take to be interesting varieties of relativism.

First, let me locate what $I$ think are the interesting varieties. Begin by distinguishing between relativism regarding truth and relativism regarding epistemic values. ${ }^{14}$ Relativism regarding truth is, roughly, the idea that what's true for one person or system can be false for another, and there just isn't any question about what's true simpliciter. This not an interesting form of relativism because it provides no space in which competing "truths" can actually compete.

Relativism regarding epistemic standards or values is the view that something which is reasonable given one set of epistemic standards can fail to be reasonable given an alternative set of standards, coupled with the denial that there is any right set of epistemic values. Epistemic relativism comes, I maintain, in two flavours: flat-out (or naive) epistemic relativism and sophisticated epistemic relativism. Flat-out epistemic relativists say there can be no basis for the claim that one set of epistemic standards is better than any other set of epistemic 
standards: all are on a par. Which set any person (or perhaps any culture) adopts is simply a matter of personal preference or of historical accident, and there can be no reasonable grounds for approving or disapproving the adoption of one rather than another set of such values. Flat-out epistemic relativism is not, as far as I'm concemed, an interesting flavour. For it provides no space in which competing epistemologies can compete in a rational way, no room for human persons of different cultures and epistemic persuasions to seek a rational accommodation of their differences.

The core idea of sophisticated epistemic relativism (which by now you've guessed is going to encompass the interesting flavours) can be expressed in the following principle:

SER There is no set of epistemic standards or criteria of which it can be said that it is uniquely correct or correct sans phrase.

On this view, one set of standards can be better or worse than another, and two differing sets can have counterbalancing strengths and weaknesses. In short, on this view, the differences between differing sets of epistemic standards are supposed to matter, even though there's no such thing as the right set. Better and worse, but no best of all.

Now it seems to me that sophisticated epistemic relativists are threatened by an inconsistency problem. For to form opinions about the relative strengths and weaknesses of differing epistemic systems, one must apply some set of evaluative standards. And, I would maintain, when one uses a particular set of evaluative standards one must assume it to be correct sans phrase. If one assumed merely that the standards one employs are correct "in one's own view" (avec phrase, at it were), one would lapse into flat-out relativism: "on my standards statement $p$ is justified, but of course on your standards it is not; and on my view my standards are correct (or are better than yours), but on your view they are not."

But the assumption that the standards one is using are correct sans phrase is inconsistent with SER. In short, the practice of sophisticated epistemic relativists on any given occasion requires them to accept some proposition inconsistent with a thesis (SER) to which, as sophisticated epistemic relativists, they are committed. Or so I would argue.

The question with which I want to leave you, then, is the question of whether such inconsistency is of a reprehensible sort.

\footnotetext{
'It is clear to me that any argument whose premiss set is demonstrably inconsistent is a bad argument. I am not sure what to say about cases in which the premisses of an argument contain an inconsistency that has not been detected, and especially the cases in which such inconsistency is very difficult to detect and where each premiss appears plausible when taken singly. My inclination is to judge this last sort of argument cogent but unsound.

${ }^{2}$ Those who construe the objects of belief as sets of possible worlds have a problem avoiding the conclusion that deductive closure is a constraint upon belief. See for example Robert Stalnaker's discussion of the deduction problem in Inquiry (Cambridge, Mass.: MIT Press, 1984), Chapter 5. Stalnaker's contention is that deductive closure is a rationality condition but not a defining condition of acceptance states (where belief states constitute one variety of acceptance states). Compare also the lengths to which Hintikka must go to avoid the
} 
conclusion that deductive closure applies to beliefs; see Jaako Hintikka, "Impossible Possible Worlds Vindicated," Journal of Philosophical Logic 4 (1975), pp. 475-484. Earlier, in Knowledge and Belief: An Introduction to the Logic of the Two Notions (Ithaca, NY: Comell University Press, 1962), Hintikka had explicitly embraced deductive closure as a condition on knowledge (see pp. 30-32).

${ }^{3}$ James Freeman has pointed out that $L$. Jonathan Cohen proposes a somewhat different solution to a similar problem in L. J. Cohen, An Essay on Belief and Acceptance (Oxford: Oxford University Press, 1992), pp. 27-32. Freeman prefers Cohen's solution to the one I propose here.

${ }^{4}$ I do not intend by this remark to endorse a "teleological" as opposed to a "deontic" approach to ethics. As I see it, what marks an approach as "deontic" is not the denial that goals are relevant to ethical evaluation, but the denial that maximizing the attainment of goals is all there is to ethical evaluation.

${ }^{5}$ It would, indeed, be better to do the thing without reference to beliefs at all. Thus one might say that the goal is to have as complete a picture as one can of the way things are, while reducing as much as possible the inaccuracies in the picture. And the completeness of the picture could be said to be measured along two dimensions: breadth and detail. I stay with belief talk in this paper mainly because it is easy to explain inconsistency in terms of beliefs, not easy to explain it in terms of pictures.

${ }^{6}$ To some degree the importance of a truth (or seriousness of error) can be gauged on the basis of the number of other truths it makes accessible to us (or the number of other errors it leads us into); but it is not clear to me whether these are the only sorts of differences that bear on the importance of a truth or the seriousness of a falsehood, even when such things are judged from an epistemic point of view. (For one thing, every proposition entails an infinite number of other propositions, so learning the truth of any contingent proposition gives us access to the truth of an infinite number of other contingent propositions to which we would not otherwise have access [e.g., for any $q, p$ entails either $p$ or $q$ ]; yet I would not want to say that every contingent truth is just as important from the epistemic point of view as every other contingent truth.) If the relative importance of truths and errors can't be settled by simply appealing to their potential for generating further truths or errors, then we probably won't be able to deal with epistemic goals in isolation or abstraction from other sorts of goals.

${ }^{7}$ Inquisitiveness might be an epistemic virtue (but then many have seen curiosity as a vice); a lack of concern for detail might be an epistemic vice (but then getting bogged down in the details often leads people to lose sight of the important points). Perhaps here, as in Aristotle's account of the moral virtues, we need something like the idea of a mean between extremes.

"E.g., inquiring into the accused's financial records (an action), ignoring the question of what the accused did on her last vacation (an omission).

${ }^{9}$ Anti-realists, who think (as Putnam does) that truth comes down to warranted assertability (that a proposition is true just in case belief in it would be justified under certain idealised conditions), are likely to find this account singularly unilluminating. That is because on their view this account of justification is trivially true. I note, however, that what is trivially true is nevertheless true.

${ }^{10}$ Assessing the degree of "guilt" in such cases gets complicated where the conclusion follows from, or is strongly supported by, a proper subset of the premisses which is consistent. I, for one, don't know how to sort the complications out in these cases.

"I assume that the well-known problems having to do with belief and will can be either solved or waived for purposes of this example.

${ }^{12}$ First presented in D. C. Makinson, "The Paradox of the Preface," Analysis 25 (1965): 205. 207. For some references to the subsequent. literature, see Sharon Ryan, "The Preface Paradox," Phil. Stud. 64 (91): 293-307. A defence of the claim that the preface paradox 
constitutes a genuine example of reasonable inconsistency can be found in Peter Klein, "The Virtue of Inconsistency," Monist 68 (1985): 105-135.

${ }^{13}$ One can quibble about what kind of impossibility this is. I doubt that it is strict logical impossibility: what creates the impossibility or inconsistency is the addition of the sentence in the preface, yet the negation of the proposition affirmed in the preface is not syntactically derivable just from the other statements in the book. Nevertheless, without appeal to any additional factual information, Jones can readily be brought to see that it's impossible that the set containing the proposition affirmed in the preface together with all and only the other propositions affirmed in the book is a set which contains only true propositions.

${ }^{14}$ See chapter 1 of Harvey Siegel's Relativism Refuted: A Critique of Contemporary Epistemological Relativism (Boston: D. Reidel Pub. Co.; 1987). Siegel distinguishes clearly between the sort of relativism defended by Hartry Field (and discussed on pp. 25-31) from the varieties of relativism involving the notion of relative truth (and discussed earlier in Siegel's chapter).

${ }^{15}$ For a more careful exploration of some of the issues raised in this paragraph, see Siegel's criticism of Hartry Field's epistemic relativism, and note Siegel's judgement on Field's version: "relativism without relative truth seems to be just as untenable as the more typical sort of relativism which incorporates some conception of relative truth. So long as evidential systems cannot themselves be neutrally or non-relatively evaluated, the incoherence problems attending relative-truth versions of relativism apply to Field's version as well" (Siegel, op. cit. p. 29).

ROBERT C. PINTO 